\title{
BLACK MIRROR NA CULTURA CONTEMPORÂNEA: O ESPETÁCULO DAS PENAS ALTERNATIVAS
}

\author{
BLACK MIRROR IN CONTEMPORARY CULTURE: THE \\ SPECTACLE OF ALTENATIVE SENTENCES
}

Wilton Garcia ${ }^{1}$

Rick José Santos ${ }^{2}$

Recebido em: 14/10/2021 Aceito em: 10/11/2021

wgarcia@usp.br ricardo.santos@ncc.edu
Resumo: Este texto problematiza a cultura contemporânea e a crescente criminalização dos segmentos mais frágeis da sociedade, ao utilizar como exemplificação a série Black Mirror, em especial o episódio "Urso Branco" (2013, 42 minutos), direção de Carl Tibbetts. O percurso metodológico organiza-se a partir do formato ensaio, a (re)considerar a dinâmica de observação, descrição e discussão. Nesse sentido, os estudos contemporâneos entrelaçam atualização e/ou inovação. Tais estudos estimulam uma desobediência epistemológica, ao compreender a produção do conhecimento, da subjetividade e da informação (fatos e/ou fake news), cujos resultados elencam a produção de efeito.

Palavras-chave: Black Mirror. Sentenças Alternativas. Populismo penal midiático.

Abstract: This text problematizes contemporary culture and recent criminalization trends of the most fragile segments of society, using as an example the Black Mirror series, especially the episode "White Bear" (2013, 42 minutes), by Carl Tibbetts. An essay format approach is adopted to (re)consider the dynamics of observation, description and discussion. In this sense, contemporary studies intertwine update and/or innovation. This approach stimulates an epistemological disobedience in the production of knowledge, subjectivity and information (facts and/or fake news), which results in the production of a new reality.

Keywords: Black Mirror. Alternative Sentences; Science fiction. Penal media populism.

\section{INTRODUÇÃO}

Victoria acorda e não sabe de nada sobre a sua vida.

Todos que encontra se recusam a falar com ela.

Imagine acordar em um lugar estranho, em que não se reconhece nem onde está ao certo. A cena inicial do episódio, "Urso Branco" (2013, 42 minutos), direção de Carl Tibbetts, da temporada dois da série Black Mirror (Netflix), levanta dúvida, inaugurando o suplício estrondoso que está por vir. Diante da câmara, procurar informações pelos cantos da casa seria, talvez, tentar ocupar a condição de sobrevivência. Perdida entre móveis e fotografias, os referentes familiares escapam à memória e pedem complementos.

Nesse caso, surge uma inquietação crítico-reflexiva provocando uma discussão em forma de pergunta: como lidar com a segmentação/segregação e a vulnerabilidade do sujeito no âmbito dos

\footnotetext{
${ }^{1}$ Faculdade de Tecnologia de Itaquaquecetuba: Itaquaquecetuba, São Paulo, Brasil

${ }^{2}$ Nassau Community College-SUNY, New York, Estados Unidos
} 
produtos culturais contemporâneos e a crescente marginalização e criminalização dos segmentos mais frágeis da sociedade, i.e. os mais pobres e as Pessoas de Cor ${ }^{3}$ ?

O presente texto problematiza a crescente criminalização dos segmentos mais frágeis da sociedade, ao exemplificar o episódio "Urso Branco". Certamente, a escolha efetiva deste episódio parte da abordagem sobre a marginalidade e vulnerabilidade da protagonista, uma Mulher de Cor como camada recorrente de direitos humanos em nossa sociedade.

O percurso metodológico aqui se organiza a partir do formato ensaio acerca dessa narrativa idiossincrática a respeito do estado democrático de direitos, no plural, a (re)considerar a dinâmica de observação, descrição, discussão e suas consequências no mundo e no ordenamento jurídico que forma a sociedade civil. Todavia, ensaiar requer (re)examinar o objeto/contexto da cena investigada em busca de validação das evidências científicas.

Nesse sentido, os estudos contemporâneos entrelaçam-se atualização e/ou inovação, estimulando uma desobediência epistemológica (MIGNOLO, 2008), na aproximação de diversos/as autores/as dos estudos culturais e das tecnologias emergentes (HARAWAY, 2013; HAYLES, 1999; QUINTARELLI, 2019). Tais estudos propõem um diálogo crítico-reflexivo com o discurso jurídico e legislativo, punitivista, neoliberal contemporâneo.

\section{BLACK MIRROR}

A série britânica Black Mirror, como produto audiovisual exibida na Netflix - plataforma de streaming que transmite conteúdos de música e/ou filme pela internet - debate a condição humana na cultura contemporânea, ao questionar o uso de recursos estéticos, técnicos e éticos das tecnologias emergentes com algoritmos, redes sociais, telefone celular, entre outros aparatos digitais para implementar medidas de controle social das mazelas.

Já na sua quinta temporada anual, trata-se de uma série televisiva de antologia em ficção científica, cujo formato traz episódios independentes. No entanto, o conjunto de episódios estrategicamente (re)equaciona atmosferas impactantes na condição adaptativa do ser humano, promovendo reflexões instigantes sobre o papel da mídia e das novas tecnologias no processo de formação de "corpos dóceis" dos "cidadão de bem" em contraste a outros corpos marginais e delinquentes (LOMBROSO, 2013).

Ressaltam-se valores entre natureza e cultura, desdobrando o enfoque na cultura contemporânea. Ou seja, pensar a respeito do futuro a partir desta ficção científica requer observar nosso presente que compreende impressões e vestígios da sociedade contemporânea (HARAWAY, 2013; QUINTARELLI, 2019). Do ponto de vista das tecnologias emergentes, a vida humana atualmente esbarra na simplicidade do viver como fio condutor de qualquer percurso enunciativo, o qual clama novidades inimagináveis - aquelas que retiram o público do lugar comum.

3 O termo "Pessoa de Cor", proveniente do termo/conceito de língua inglesa People of Color, é utilizado aqui como termo inclusivo-plural, para designar grupos de indivíduos não-brancos (negros, latinos de todas as etnias, indígenas, asiáticos, mestiços, etc.). Esse termo foi adotado nos EUA, durante a década de 1970, por ativistas e acadêmicos radicais não-brancos, como forma de ressignificação e reapropriação cultural e tática política de coalisão. 
A multiplicidade que a ficção científica atribui à experiência só é possível de ser compreendida por procedimentos transdisciplinares. (...) Na base dessa estratégia está a busca de compreender o real como múltiplo, como hipercomplexo e, portanto, irredutível aos métodos simplificadores de cada ciência isoladamente (OLIVEIRA, 2005, p. 118).

A experiência na cultura contemporânea solicita flexibilidade para atingir o fluxo hipercomplexo, como cita Oliveira (2005). Black Mirror pode ser visto/lido como produto cultural empacotado e vendido pelo populismo penal midiático contemporâneo. Seria, então, um convite aos desafios percepto-cognitivos sobre as transformações promovidas pela cultura contemporânea.

Variantes necessárias para a contemporaneidade pulsam estados de diversidade, alteridade, diferença pluralidade, multiculturalismo. Em Black Mirror, um autêntico simulacro permite obter a ficção como referente para ser visto/lido e julgado, de acordo com a interpretação do público que assiste atrocidades tecnológicas pautadas por situações estapafúrdias.

No entorno tecnológico, os eixos de Black Mirror convocam esferas, mais profundas, do pensamento humano acerca da realidade virtual e de questões ético-jurídicas emergentes. No presente, tais questões deveriam evidenciar a Lei de Proteção de Dados (LPD), para assegurar as garantias individuais num futuro "Estado de Direito Techno-Virtual". Ou seja, o tecido tecnológico da ficção científica potencializa a trama social tendo a intensidade poética como leitmotiv dessa série audiovisual, encobrindo as artimanhas da exploração do consumo capitalista. Sendo assim,

(...) alterar a produção de conhecimento e a produção de subjetividade requer (re)considerar as articulações expostas por esse produto audiovisual, uma vez que sua narrativa impacta o público a partir da produção de informações desencontradas pela intensidade da experiência (MANDUCA; GARCIA, 2020, p. 55).

Se os episódios de Black Mirror são assustadores e, ao mesmo tempo, inovadores, de acordo com Lemos (2018) e Berto (2017), as representações espaciais/temporais de presente, passado e futuro, na tela, exploram a dependência sintomática desses espelhos escuros com fragmentos que, aos poucos, dissipam informações e posicionamentos díspares. Isso desafia o uso da linguagem tecnológica nas produções culturais contemporâneas, valorizando o reflexo das imagens quebradas, aos pedaços, que se propagam da fragmentação caleidoscópica do espelho estendido como metáfora.

O que amplia expressivamente o campo de visão, em seu (des)dobramento profundo. Dessa maneira, a reverberação da imagem fragmentada extrapola a lógica de uma narrativa fechada, com início, meio e fim. A ideia seria fragmentar para fragilizar e, consequentemente, dominar. O contexto parece ser um lugar esvaziado de qualquer referente visual mais plausível. No enredo, não se encontra coerência nas informações. Há bastante fragmentação e imprecisão nos fatos. Sem afeto ou sentimento, pouco se consegue estabelecer um vínculo capaz de trazer aconchego. Nesse caso,

A dinâmica do jogo entre a fragmentação e a homogeneidade é fundamental para o desenvolvimento da opressão, agora, sob 
representação abstrata do espaço possível. Nessa condicional cria-se uma coordenada em cujo espaço primordial e preexistente a vida cotidiana se desenrola. No entanto, as desigualdades sociais à medida que as pessoas vivem e se acomodam nas coordenadas, aglomerando-se nos mais variados agrupamentos (nações, bairros, favelas e guetos, Primeiro e Terceiro Mundos) (SANTOS, 2014, p. 35-36).

As desigualdades sociais, assim, são reflexos de fracassos nessas arestas sociais que perpassam o sistema hegemônico, sem conseguir escapar das dificuldades, dos problemas, dos desafios. O desigual desequilibra a equidade, (re)afirmando posições distintas. A compreensão de níveis desiguais gera resultados desiguais, quase impossíveis de escapar do seu ciclo. Ou seja, são histórias de vidas engolidas, cooptadas pelo capitalismo (MARX, 1967), cada vez mais usurpador das tecnologias emergentes a seu favor. Consequentemente, esse jogo de coordenadas irregulares não é formatado por estados abstratos, longe de uma abstração essencialista. Pelo contrário, são articulações dinâmicas do capitalismo que estrategicamente enfocam o consumo em prol do chamado mercado-mídia, abastecido de informação.

Em Black Mirror, a voracidade tenaz do consumo abarca o mercado-mídia confundindo informação e entretenimento. Contudo, entreter seria mais que passar o tempo. Reconhecer a condição humana contribui para se pensar sobre a fragilidade do sujeito contemporâneo perante adversidades e enfrentamentos do sistema capitalista (MARX, 1967), com suas estruturas e instituições de controle das mazelas sociais (GARLAND, 2001).

Isto é, essa série audiovisual descontextualiza e transforma fatos concretos de contextos históricos complexos em um espetáculo simplório de horror e violência, sem compromisso com a ética. Paradoxalmente pautado pela produção de efeito cinematográfico, tal proposição narrativa solicita ética - na combinação mediada pelas relações humanas e pelo ordenamento jurídico humanizado, no qual o direito de propriedade jamais pudesse ter primazia aos direitos e garantias fundamentais do Ser humano, independente de classe, raça, gênero, ou orientação sexual.

\section{O EPISÓDIO}

Na segunda temporada de Black Mirror, o episódio "Urso Branco" (White Bear) contém uma sinopse concisa e, ao mesmo tempo, enigmática - destacada como epígrafe na abertura de nosso presente texto. A sinopse apresenta a personagem de forma bastante sucinta, em três movimentos: o despertar, o saber e a negação. Sem dúvida, é uma proposta de enredo que pede complemento. São movimentos distintos que se complementam, uma vez que a sequência narrativa solicita atenção do/a espectador/a. Ou seja, situações complexas geram distopias (AZAMBUJA; PERRI, 2018), porque causam estranhamento, na abordagem que revela a protagonista.

Ainda que, o desempenho performativo de Victoria Skillane (interpretada por Lenora Crichlow) está em xeque, uma articulação de valores e referentes distópicos (AZAMBUJA; PERRI, 2018) relaciona cognição, consciência e inteligência - entre o despertar, o saber e a possibilidade de escolha (livre manifestação da vontade). Ela acorda e se depara sentada em uma cadeira do quarto, no segundo andar de um sobrado, sem bem reconhecer o ambiente. Fotos familiares indicam que 
seria sua casa. Mas, há um determinado desassossego. Percebe comprimidos no chão, sugerindo entorpecimento para forçar o sono ou uma possível tentativa fracassada de suicídio (ou fuga). A cena estranha parece ser insana, mas reflete aquela realidade, submetida ao fracasso de tentar escapar do absurdo requinte de crueldade.

De imediato, Victoria surge em uma complexa zona de conflito, numa encenação completamente articulada. Mais à frente, o/a espectador/a percebe que tudo isso é proposital: os movimentos de Vitória são minuciosamente controlados pelo contexto e pelas outras pessoas com quem interage. Portanto, acomoda-se a narrativa atravessada pela tensão da personagem sendo desumanizada, em razão de uma perseguição desenfreada. Parece ser uma lógica quase invertida, pois não há tempo para acomodar a situação complexa e, ao mesmo tempo, delicada.

Após explorar todo o ambiente privado/doméstico em busca de possíveis pistas que possam Ihe devolver sua subjetividade cancelada, Victoria decide sair para a rua e se depara com uma esfera pública esvaziada. As ruas da vizinhança encontram-se completamente vazias e a personagem observa que está sendo observada por toda parte. Silenciosamente, as pessoas capturam seus movimentos por trás de cortinas, janelas e câmeras de telefones celulares.

A velocidade extrema da narrativa, quase sem pausa, impacta a metapercepção do público, que tensamente observa a personagem sendo observada e caçada como um animal numa jaula de prisão/reserva zoológica, num safari de perseguição, cujos ambientes e as ações mudam rapidamente. Ao tentar se situar no desenvolvimento do enredo, aos poucos o/a espectador/a vai sendo deslocado da posição de cumplice da sociedade de observação e passa, junto com essa a protagonista negra/Latina, a buscar o sentido de sua existência nesse contexto absurdo. Seu estado de vulnerabilidade vai sendo exposto em cada parte da trama, como etapas de videogames, a ser conquistada.

Segundo Berto (2017, p. 13)

Que somos técnico-dependentes, subordinados aos meios de comunicação social e habitantes de uma única aldeia globalmente interconectada acredito que não reste a menor dúvida, assim como indubitável também é a certeza que chegamos em um ponto onde não existe volta e no qual esses três pilares continuarão a sustentar nossa sociedade e a determinar nosso estilo de vida. Portanto se não há como mudar o panorama que posto já está, nos resta repensar a forma com que consumimos tais redes e aplicativos sociais e a maneira com que as informações ali por nós postadas pode e deve ser utilizada.

Ou seja, Victoria com seu papel do sujeito de direitos é compreendido como simulacro (hiper)midiático de um jogo de punição perversa, cuja escopofilia (desejo absurdo de observar) é constante. Quem observa é um grupo expressivo de pessoas que permanecem mudas em cena, interessadas unicamente em registrar os fatos com seus telefones celulares: as testemunhasvigilantes de uma perseguição cruel e desumana que se inicia no momento em que a personagem deixa o confinamento do seu suposto lar em busca de algum tipo de esclarecimento sobre a sua condição de pertencimento. 
Nesse momento é introduzido um terceiro elemento/personagem de absurdo na trama: do nada aparecem três vigilantes caricatos, fortemente armados, que, sem nenhuma explicação passam, literalmente, a caçar a personagem, reduzindo seu status de Ser humana ao de um animal nãohumano. Essa abordagem impede qualquer tipo de aproximação e/ou contato com a personagem principal, que se encontra em sofrimento diante de uma perseguição insana.

A construção dessa narrativa audiovisual é artificial: um simulacro ou uma crônica de um crime anunciado. Seria, sim, um verdadeiro show de populismo penal midiático. Algo arquitetado anteriormente para ser executado conforme a espetacularidade performatizada acontece a cada manhã despertada por Victoria.

No final da caçada, percebe-se o tom alegórico da narrativa que conclama a teatralidade cênica desse populismo penal midiático. Sobem as cortinas que revelam um palco, onde o corpo de Victoria é acorrentado em uma cadeira (elétrica), por seus algozes, sob os aplausos do público, em cena. Somente no final do episódio, a plateia se dá conta que esse espetáculo de perseguição é uma reiteração que se repete a cada dia, quando a personagem desperta para sua realidade de prisioneira.

Desde o início desse processo insolente, Kafkaniano, a protagonista/ré já está fadada ao fracasso. É uma linha de experiências traumáticas, um suplício apavorante porque não há desfecho. Como se o cotidiano estivesse (de)marcado para ser reprimido e vencido, seria uma brutalidade explorar a dor desse cenário programado pela violência. Neste episódio, Victoria desperta solitária, isolada e alienada de tudo e todos. Não tem destino certo além do fracasso, porque retorna ao começo diariamente, sem conseguir avançar na ida.

Nessa trama macabra, há um acréscimo mínimo em sua memória que percebe certas lembranças entrecortadas. Mas, são apagadas com doses de remédios. As evidências narrativas demonstram o insucesso da protagonista condenada. Nada escapa naquele contexto, pois não há alternativa, nem saída. Não seria possível, então, pensar uma solução. Há apenas o designo recorrente do fracasso.

O/a espectador/a, então, desperta do fato de que toda a espetacularização da perseguição faz parte de um processo alternativo de pena privativa de liberdade futurista de tal populismo penal midiático. Nele, a ré, condenada por crime de sequestro e homicídio o doloso, é forçada a reviver cena análoga a seu crime diariamente numa penitenciária/parque temático experimental, onde cidadãos pagam ingressos para terem o direito de assistir e participar (registrando com as câmeras de seus telefones celulares) no processo de execução penal.

\section{DISCUSSÃO}

Eis um processo coletivo de vingança e de punição perversa e suplício do corpo do condenado (FOUCAULT, 1987), que se estende aos demais participantes que assistem. Estão todos/as presos/as à narrativa ininterrupta como ciclo vicioso. A pena privativa de liberdade é desprovida da pretensão de ressocialização de uma delinquente, ou mesmo da necessidade de 
proteção da sociedade, assumindo, sem qualquer reserva moral ou ética, a condição de produto hipermidiático - de vingança e espetáculo.

O episódio exibe, como tema central o fracasso e a obsoletismo da instituição da penitenciária, como argumentou a ativista negra estadunidense, Angela Davis (2003). Uma vivência da perda, em conflito. Provavelmente, seria uma vida, ou um segmento da população, armada para a derrota, em que a robotização repetitiva apenas cumpre a rotina de tentar buscar o que está prédefinido?

Mais que isso, a protagonista/criminosa, nesse caso, é uma vítima, presa ao comando do sistema, artificialmente, elaborado para ser punitivo. Não se consegue fugir do estabelecido, porque já está dado. O espetáculo do processo é apenas encenação, cuja sentença final já está definida desde o início. Ela encontra-se presa àquela punição (CORTELLA, 2005; GOFFMAN, 2001).

A reincidência torna-se uma (metáfora) constante recorrente, como uma espécie de condenação histórica e perversa, diante da ausência de qualquer atributo para ultrapassar esse sistema e superar. A narrativa retoma diariamente, em ciclo, sem avançar. Seria uma profunda estagnação que não remete a lugar algum.

O campo de possibilidades oferecidas pelo episódio escolhido para esta leitura críticoreflexiva encontra a lógica ficcional de entretenimento tecnológico produzindo pela indústria do populismo penal midiático. Deliberadamente, esse campo de possibilidades flexiona e tangencia a impossibilidade. Ou seja, o crime hediondo, esse produto cultural, equivale-se das memórias alteradas da protagonista, para indagar a respeito das coisas no mundo, manipulando a realidade para forçar a protagonista/ré a participar ativamente de sua sentença/pena/suplício.

Sua ausência de memória no o episódio "Urso Branco" dificulta criar conexões para sair desse labirinto, como metáfora (das figuras de linguagens), que esbarra em provocações incompreensíveis. Nessa ausência de memória ciborgue (HARAWAY, 2013; HAYLES, 1999; QUINTARELLI, 2019), desatinos abruptos de entrecortes secos: flashs, lapsos, lacunas, hiatos, gaps. São breves explosões audiovisuais como choques de uma inteligência artificial, com defeito. Ausência de memória e fracasso da vítima/criminosa é uma combinação pertinente para pensarmos na espetacularização da pena privativa de liberdade e da instituição da penitenciária desde sua concepção no século XVIII (FOUCAULT, 1987).

Se nossa inquietação crítico-reflexiva seria discutir a questão do direito que tange a vulnerabilidade do sujeito no âmbito dos produtos culturais contemporâneos, a relevância desta investigação aponta para a produção de conhecimento, subjetividade e informação, cujos resultados obtidos elencam a produção de efeito na cultura contemporânea. Isso entrecruza a produção de conhecimento, subjetividade e informação como efeito na cultura contemporânea.

Nesse fluxo da cultura contemporânea, a produção de informação (fatos e/ou fake news) permeia um jogo narrativo envolvente que trabalha a mediação entre os participantes em cena: protagonista, coadjuvantes, observadores, caçadores, vítimas e criminosos, juízes e réus. Considere que, no campo da cultura e da comunicação, a informação contribui para a circulação e a disseminação, assim como para a criação, dos fatos numa era de pós-verdade (QUINTARELLI, 2019). 
No campo das ciências humanas, a (re)dimensão de sujeito cada vez mais torna-se fator fundamental para se organizar o estado democrático de direitos, no plural, conforme indicado na introdução deste ensaio. "Será que justiça persegue todos os crimes sem distinção de classe econômica?" (SANTOS, 2021, p. 3).

De modo sensato e ponderado, gerar uma perspectiva questionadora acerca do sistema hegemônico sempre será um ponto fundamental para a justiça. Esta última deve se valer dos direitos e da dignidade da pessoa humana independente de classe, raça, religião, geografia, orientação sexual.

\section{CONSIDERAÇÕES FINAIS}

Ao questionar a fronteira entre os espaços públicos e privados, entre o direito de punir do Estado e os direitos fundamentais dos seres humanos, o episódio "Urso Branco" estabelece conexões que amparam as pessoas e seus direitos individuais como fator social de um bem coletivo, compartilhado socialmente. Assim, evitar a violação dos direitos humanos seria garantir um posicionamento de contramão, em permanente conflito contra os interesses do protocolo regulador.

Tal episódio coloca em evidência hipermidiática e suas interconexões com o racismo estrutural, a cultura de cancelamento contemporânea, a criminalização da pobreza e o boom do complexo industrial da prisão (DAVIS, 1998). Diante do populismo penal midiático, a segregação do sujeito contemporâneo destaca as desigualdades sociais com a crescente marginalização e criminalização dos segmentos mais frágeis da sociedade.

Com efeito, a protagonista Victoria - como Mulher de Cor - luta para sobreviver ao caos. 


\section{REFERÊNCIAS}

AZAMBUJA, P.; PERRI, C. Filosofia e distopia seriadas: sobre Black Mirror e suas relações entre humanos e técnicas. Ícone, v. 16, n. 1. 2018. Disponível em:

https://periodicos.ufpe.br/revistas/icone/article/view/237077/pdf. Acesso em 7 jun 2021.

BERTO, M. A sociedade e seu reflexo: uma análise do seriado Black Mirror à luz do pensamento McLuhaniano. Anais do 40 Intercom. 2017. Disponível em:

http://portalintercom.org.br/anais/nacional2017/resumos/R12-1625-1.pdf. Acesso em 9 jun 2021.

CORTELLA, M. S. Recusar a destruição da convivência digna! (valores inadiáveis). In PASSETTI, P.; OLIVEIRA, S. A tolerância e o intempestivo. Cotia, SP: Ateliê Editorial, 2005. p.169-179

DAVIS, A. Are prisions obsolete? New York: Seven Stories press, 2003.

DAVIS, A. Masked racism: reflections on the prison industrial complex. ColorLines, Fall 1998. Disponível em: http://www.ruf.rice.edu/ loveassc/fellows/Prisons.pdf. Acessado em: 01 jan 2021.

FOUCAULT, M. Vigiar e punir: história de violência nas prisões. 8 ed. Petrópolis: Vozes, 1987.

GOFFMAN, E. Manicômios, prisões e conventos. $7^{\text {a }}$ ed. São Paulo: Perspectiva, 2001.

HARAWAY, D. Manifesto ciborgue. In: TADEU, T. (Org) Antropologia do ciborgue. Belo Horizonte: Autêntica, 2013, p. 33-118.

HAYLES, N. K. How we became posthuman: virtual bodies in cybernetics and informatics. Chicago: Chicago University Press, 1999.

LEMOS, A. Isso (não) é muito Black Mirror: passado, presente e futuro das tecnologias de comunicação e informação. Salvador: Edufba, 2018.

LOMBROSO, C. O homem delinquente. São Paulo: Ícone, 2013.

MARX, K. Capital, vol. 1, New York: International Publishers, 1967.

MANDUCA, A.; GARCIA, W. Ciborgues e Black Mirror na cultura contemporânea. Revista de Estudos Universitárias, Sorocaba, v. 46, p. 39-57, 2020.

MIGNOLO, W.D. Desobediência epistemológica: a opção decolonial e o significado de identidade em política. Cadernos de Letras da UFF, n. 34, p. 287-324, 2008. 
OLIVEIRA, F. R. Como a ficção científica conquistou a atualidade: tecnologias de informação e mudanças na subjetividade. Revista Intercom. São Paulo, v. 28, n. 2, p. 101-122, 2005. Disponível em: http://portcom.intercom.org.br/revistas/index.php/revistaintercom/article/view/385. Acesso em 9 jun 2021.

QUINTARELLI, S. Instruções para um futuro imaterial. São Paulo: Elefante, 2019.

SANTOS, R. O "novo normal" e a criminalização da juventude periférica: educação, tecnologia, trabalho e sociedade em tempos de pandemia. Anais do Seminário Internacional De Tecnologia, Educação e Sociedade. Fatec Itaquaquecetuba, 2021. Disponível em: https://sidtes.wordpress.com/anais-2021-2/. Acessado em: 9 jun 2021.

SANTOS, R. Poética da diferença. São Paulo: Hagrado, 2014.

URSO Branco - Black Mirror. Dir.: Carl Tibbetts. Rot.: Charlie Brokker. El.: Lenora Crichlow. EUA/Inglaterra: 2013, série de TV, Netflix (42 min.), som, color. 